Int. J. Electrochem. Sci., 14 (2019) $2804-2814$

International Journal of

ELECTROCHEMICAL

SCIENCE

WWW.electrochemsci.org

\title{
Conformal Carbon Coating on Hard Carbon Anode Derived from Propionaldehyde for Exellent Performance of Lithium-Ion Batteries
}

\author{
Longfeng Hu, Gang Cheng, Jingrun Ren, Fuming Wang ${ }^{*}$, Jianguo Ren* \\ BTR new energy materials inc., Shenzhen, China 518106 \\ "E-mail: wfm@btrchina.com, renjianguo@btrchina.com
}

doi: $10.20964 / 2019.03 .75$

Received: 2 November 2018 / Accepted: 19 December 2018 / Published: 7 February 2019

\begin{abstract}
Hard carbon anode material is one of the most promising candidates for next-generation lithium-ion batteries with high power performance. Nevertheless, the poor conductivity and low initial Coulombic efficiency largely impede its commercial implementation. Herein, we demonstrate the utilization of propionaldehyde as a new coating precursor for synthesizing a core-shell structured hard carbon material by a chemical vapor deposition (CVD) coating route. The surface of the hard carbon can be evenly coated with a thin carbon layer of $0.5 \sim 2 \mu \mathrm{m}$ in thickness. The powder conductivity measurement shows that the coated carbon shell can effectively improve the conductivity of the hard carbon from 27.3 to $36.3 \mathrm{~S} \mathrm{~cm}^{-1}$. Further, the resultant core-shell structured product shows enhanced lithium storage performance. Especially, the electrode with high areal mass loading of over $5 \mathrm{mg} \mathrm{cm}^{-2}$ can deliver a large reversible capacity of $404.3 \mathrm{mAh} \mathrm{g}^{-1}$ and a high initial Coulombic efficiency of $85.2 \%$, representative of the increment of $79.1 \mathrm{mAh} \mathrm{g}^{-1}$ and $10.1 \%$ with respect to the uncoated counterpart, respectively. Importantly, coupled with a commercial NCM523 cathode, the full battery (18650 type) displays excellent cyclic stability with a low capacity decay of $\sim 0.012 \%$ per cycle over 800 charge-discharge cycles at high rates of $6 \mathrm{C} / 6 \mathrm{C}$. We suggest that the CVD coating treatment by using propionaldehyde as a carbon precursor is an effective method in improving the overall electrochemical properties of hard carbon anodes for lithium-ion batteries.
\end{abstract}

Keywords: hard carbon, core-shell structure, propionaldehyde, chemical vapor deposition, lithium-ion batteries.

\section{$\underline{\text { FULL TEXT }}$}

(C) 2019 The Authors. Published by ESG (www.electrochemsci.org). This article is an open access article distributed under the terms and conditions of the Creative Commons Attribution license (http://creativecommons.org/licenses/by/4.0/). 